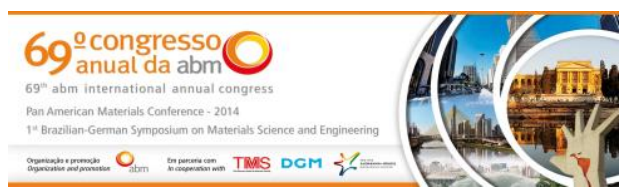

Tema: Materiais cerâmicos, compósitos e poliméricos

\title{
PREPARAÇÃO E CARACTERIZAÇÃO DAS PROPRIEDADES DE TIJOLOS DE SOLO-CIMENTO*
}

\section{Resumo}

Elcio Correia de Souza Tavares ${ }^{1}$ Danilo Duarte Costa e Silvar ${ }^{2}$

No estado do RN o êxodo da população residente na zona rural para a zona urbana ocorre de forma ainda acentuada, tendo como agravante o ciclo de secas periódicas. Outro problema do estado é a desertificação, que vem tomando proporções maiores ao longo dos anos, e em algumas regiões específicas, gera relevante preocupação ambiental, uma vez que as cerâmicas ali presentes utilizam a vegetação local como combustível nos fornos de tecnologia tradicional. Embora se tenha consciência deste problema, pouco se percebe em termos de iniciativa para saná-lo, uma vez que o setor é marcado pela baixa tecnologia empregada. Uma alternativa para a construção de residências para a população de baixo poder aquisitivo é a utilização de tijolos feitos de solo-cimento. O solo-cimento é uma mistura íntima e bem proporcionada de solo com cimento Portland, de tal modo que haja uma estabilização daquele por este, melhorando as propriedades da mistura. $\mathrm{O}$ tijolo feito de solo-cimento é caracterizado por um menor custo final que o tradicional e pela baixa agressão ao meio ambiente, uma vez que não é queimado. Neste trabalho foram produzidos tijolos de terra crua misturada com cimento (20\% a $30 \%$ ) e compactados em prensa manual. Foram realizados análises dos materiais empregados e de resistência à compressão dos tijolos produzidos. Verificou-se que o tijolo de solo-cimento possui resistência a compressão dentro das normas e facilidade de fabricação, proporcionado assim uma solução alternativa para o setor.

Palavras-chave: Solo-cimento; Meio ambiente; Habitação popular.

\section{PREPARATION AND CHARACTERIZATION OF PROPERTIES OF SOIL-CEMENT BRICKS}

\section{Abstract}

In the state of RN the exodus of the population residing in rural areas to the urban area is still worrying, with the aggravating cycle of periodic droughts. Another problem is the desertification that has taken over the years major proportions, and in some specific regions, generates significant environmental concern, since there ceramics using the present location vegetation as fuel in furnaces traditional technology. Although one is aware of this problem, little is perceived in terms of initiative to remedy it, because the sector is characterized by low technology employed. An alternative to building homes for people with low purchasing power is the use of bricks made of soil-cement. The soil cement is an intimate, well-proportioned mixture of Portland cement with the soil, so that there is stabilization by this, improving the properties of the mixture. The brick made of soil-cement is characterized by a lower cost than the traditional and low aggression to the environment, because it is not burned. In this work bricks raw soil mixed with cement (20\% to $30 \%)$ were produced and packaged in a manual pressing machine. Analysis of the materials used and the compressive strength of bricks produced were performed. It was found that the soil-cement brick has compressive strength within the Brazilian standards and it is easy to manufacturing, thereby offering an alternative solution for the sector.

Keywords: Soil-cement; Environment; Popular housing.

1 Físico, doutor, professor, Engenharia Civil, Universidade Potiguar, Natal, RN, Brasil.

2 Engenheiro Civil, mestre, doutorando, Engenharia Civil, Universidade Potiguar, Natal, RN, Brasil.

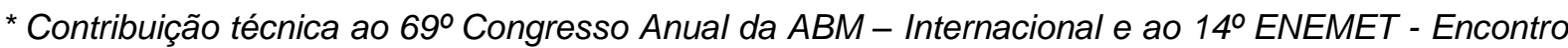
Nacional de Estudantes de Engenharia Metalúrgica, de Materiais e de Minas, 21 a 25 de julho de 2014, São Paulo, SP, Brasil.
} 


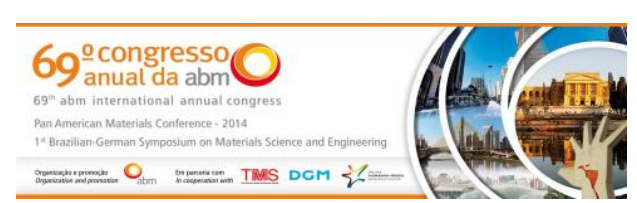

\section{INTRODUÇÃO}

O setor ceramista do RN é tradicional e com processos rudimentares, possuindo uma qualidade duvidosa de produto final e sem nenhuma inovação tecnológica.

No estado do Rio Grande do Norte ele é parte importante da economia local. Porém, é extremamente atrasado em termos de tecnologia e com carência de mão de obra especializada, sendo caracterizado pelo modo de produção tradicional, necessitando urgentemente de alternativas e inovações tecnológicas. $O$ modo de produção (predominantemente na grande maioria das cerâmicas do estado) com utilização de lenha como combustível tem proporcionado como consequência a degradação do meio ambiente. Em 2006, a energia consumida, para uso industrial, foi estimada em 3,5 milhões de Toneladas Equivalentes de Petróleo (TEP), o que corresponde a $11,6 \mathrm{MWh}$. A lenha como fonte energética representou quase $50 \%$ de todo o consumo [1].

A falta de inovação tecnológica no setor ceramista também prejudica a população de baixa renda, pois o gasto com combustível e demais gêneros do processo tradicional proporciona a inviabilidade de valor do produto final para as camadas mais desfavorecidas, fato que atua diretamente para aumentar o déficit habitacional Nordestino, que é junto com a região norte o maior do Brasil.

O tijolo de solo-cimento ou terra crua é produzido sem queima, tendo assim vantagens em relação ao tradicional: Baixo custo final, redução da emissão de gases na atmosfera, sem corte de lenha, simplificação do processo e redução do tempo de construção.

Este trabalho apresenta uma tecnologia alternativa de fabricação de tijolos para o setor ceramista, não agressiva ao meio ambiente e de baixo custo final, tendo como objetivos preparar tijolos prensados estabilizados com cimento Portland, analisar suas propriedades e comparar o produto com o tijolo tradicional.

\section{MATERIAIS E MÉTODOS}

\subsection{Materiais}

Os materiais usados foram terra e cimento. Foi usada terra comum na cidade de Natal, extraída de uma profundidade de cerca de cinquenta centímetros.

O cimento empregado foi o cimento composto com pozolana, CPIIZ-32, disponível no comércio local. Foi feita análise granulométrica dos diversos materiais empregados na fabricação dos tijolos e em seguida foi feita a mistura de terra crua misturada com cimento (20\% a $30 \%)$. Os tijolos foram então compactados empregando-se prensa manual. Suas dimensões foram de $6,8 \mathrm{~cm} \times 11 \mathrm{~cm} \times 23 \mathrm{~cm}$. A secagem era feita em local coberto.

\footnotetext{
* Contribuição técnica ao $69^{\circ}$ Congresso Anual da ABM - Internacional e ao 14ํㅡㄹ ENEMET - Encontro Nacional de Estudantes de Engenharia Metalúrgica, de Materiais e de Minas, 21 a 25 de julho de 2014, São Paulo, SP, Brasil.
} 

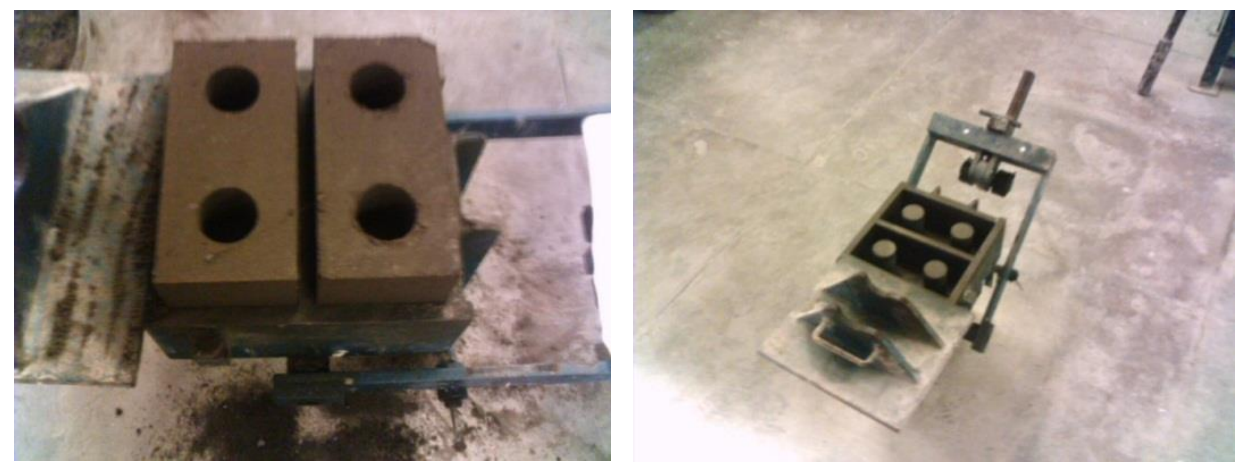

Figuras 1 e 2 - Bloco moldado e prensa manual utilizada

A resistência à compressão dos tijolos foi medida conforme a norma NBR 8492 [2], utilizando prensa marca EMIC modelo M. U. E. 100.

\section{RESULTADOS E DISCUSSÃO}

A figura 3 mostra que os valores de resistência à compressão dos tijolos produzidos sem queima, embora menores que os dos queimados, estão de acordo com os exigidos pelas normas brasileiras.

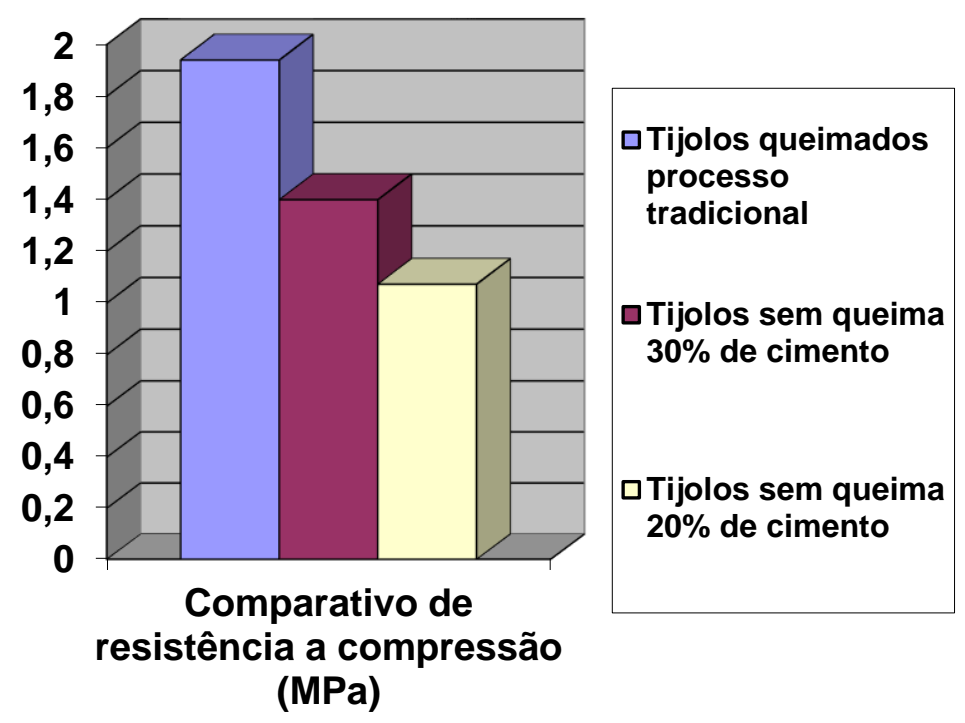

Figura 3. Comparativo da resistência à compressão dos tijolos queimados pelo processo tradicional e tijolos prensados sem queima.

O comparativo de tijolo terra crua prensado sem queima com o tijolo tradicional com queima mostra que a diferença entre eles ficou em torno de 0,4 MPA no primeiro bloco, no entanto essa resistência, embora menor, está dentro das normas de produção e portanto adequada a sua fabricação e posterior comercialização por parte da cerâmica.

A tabela 1 mostra que na amostra de terra utilizada um percentual mínimo de material passou na peneira 200. Tal fato diminui consideravelmente a resistência à compressão. Assim, pode-se esperar um ganho na resistência ao efetuar-se uma moagem mais demorada no material.

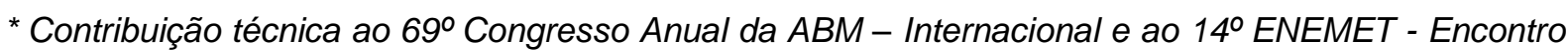
Nacional de Estudantes de Engenharia Metalúrgica, de Materiais e de Minas, 21 a 25 de julho de 2014, São Paulo, SP, Brasil.
} 
Tabela 1. Análise granulométrica do material utilizado

\begin{tabular}{c|c}
\hline Peneira No & Peso (g) \\
\hline 16 & 1,57 \\
\hline 30 & 17,42 \\
\hline 40 & 90,53 \\
\hline 50 & 181,46 \\
\hline 100 & 180,36 \\
\hline 200 & 24,66 \\
\hline
\end{tabular}

\section{CONCLUSÃO}

Tijolos de terra crua podem ser produzidos utilizando-se a terra comum de Natal (RN). Os valores da resistência à compressão, embora menores que os queimados, estão dentro dos permitidos pelas normas. A resistência pode ser aumentada através da moagem dos constituintes do tijolo.

\section{REFERÊNCIAS}

1 SEBRAE. Cerâmica Vermelha: Estudo de mercado 2008.

2 ASSOCIAÇÃO BRASILEIRA DE NORMAS TÉCNICAS - NBR 8492 - Tijolo maciço de solo-cimento. Determinação da resistência à compressão e da absorção de água. Método de Ensaio. Rio de Janeiro, 2012.

\section{BIBLIOGRAFIA}

1 Souza MIB, Segantini AAS, Pereira JA. Tijolos prensados de solo-cimento confeccionados com resíduos de concreto. Rev. Bras. Eng. Agr. e Amb., 2008; 12(2): 205-212,.

2 Vieira A, et al. Estudo do processo de obtenção e caracterização de tijolos de solo-cimento. Cerâmica Industrial, 2007; 12(6): 47-50.

3 Ay N, Ünal M. The use of waste ceramic tile in cement production. Cement and Concrete Res., 2000; 30: 497-499.

4 Lima Júnior HC, Willrich FL, Barbosa NP. Structural behavior of load bearing brick walls of soil-cement with the addition of ground ceramic waste, Rev. Bras. Eng. Agr. e Amb., 2003; 7(3): 552-558.

\footnotetext{
* Contribuição técnica ao $69^{\circ}$ Congresso Anual da ABM - Internacional e ao 14ํㅡㄹ ENEMET - Encontro Nacional de Estudantes de Engenharia Metalúrgica, de Materiais e de Minas, 21 a 25 de julho de 2014, São Paulo, SP, Brasil.
} 